\title{
Oral Squamous Cell Carcinoma: Diagnosis and Treatment Planning
}

\author{
Vijay Deshmukh and Kishore Shekar
}

\subsection{Background and Incidence}

The incidence of oral and oropharyngeal SCC is on the rise. Each year approximately 263,000 new cases of oral cancer are detected worldwide, and 127,000 people die of the disease [1]. In India it is the third most common cancer and accounts for almost $40 \%$ of deaths. Among men it is the second most common site, and in women it is the fourth in India [2]. In 2012, the incidence rate for male was $10.1 / 1,00,000$ and for female 4.3/1,00,000 [3].

\subsection{Introduction}

Oral carcinoma commonly called as the oral squamous cell carcinoma (OSCC) occurs as an ulceroproliferative lesion of the oral mucosa affecting any site starting from the lips to the oropharynx. The commonest sites are gingivobuccal sulcus of mandible followed by the tongue and floor of the mouth. It should be understood that Indian cancer is much different to other parts of the world. The habit of the tobacco chewing (smokeless tobacco) and pan masala, i.e., a mixture of the tobacco, betel nut, and unknown chemicals used for the color and flavors, is the commonest cause. Classical Indian cancer is the gingivobuccal sulcus (GBS) of the mandible due to the

Electronic Supplementary Material The online version of this chapter (https://doi.org/10.1007/978-981-15-1346-6_81) contains supplementary material, which is available to authorized users.

V. Deshmukh $(\triangle)$

Maxillofacial and Microvascular Surgeon, Deshmukh Institute of Maxillofacial Surgery and Research Centre, Aurangabad, India

Department of Dentistry and Maxillofacial Surgery, JIIU'S Indian Institute of Medical Sciences, Maharashtra, Jalna, India

K. Shekar

Head and Neck Surgeon (OMFS), Ninewells Hospital and Dundee

University Medical School, Dundee, UK

e-mail: Kishore.Shekar2@nhs.scot placement and holding of the tobacco-lime mixture, in the area. Over the last three decades, pan masala has become popular, due to the easy availability in pre-mixed packed. This maybe chewed or kept in the oral cavity, i.e., GBS, which leads to continuous action of the contents on the oral mucosa. The constant irritation leads to fibrosis and with time results in submucous fibrosis.

\subsection{Etiology of Oral Carcinoma}

Etiology of oral SCC is multifactorial. Local irritants contribute significantly to the conversion of a premalignant process to invasive carcinoma. Damage to the epithelial layer followed by the basement membrane and submucosa secondary to chemical and mechanical injury leads to fibrosis of the mucous membrane.

The prominent etiological factors are:

1. Tobacco consumption-All forms of tobacco smoke as well as smokeless have carcinogenic potential. Evidence for smokeless tobacco causing oral and pharyngeal cancer was evaluated and confirmed [4]. India is the third largest producer and consumer of smoked and smokeless forms of tobacco. Tobacco-related cancers account for nearly $50 \%$ of all cancers among men and $25 \%$ of all cancers among women with the burden of tobacco-related cancers in 2001 estimated to be nearly 0.33 million cases annually. It has been predicted that an incidence of sevenfold increase in tobacco-related cancer is expected between 1995 and 2025 resulting in an increase by $220 \%$ of cancer deaths simply related to tobacco use [5]. In India chewable tobacco is consumed in various forms. The traditional form is called the pan (Figs. 81.1, 81.2 and 81.3). Local form of smoking tobacco is called as bidi, which is a crude form of cigarette. This is considered to be more carcinogenic. It commonly causes carcinoma of the palate, oropharynx, and larynx. 


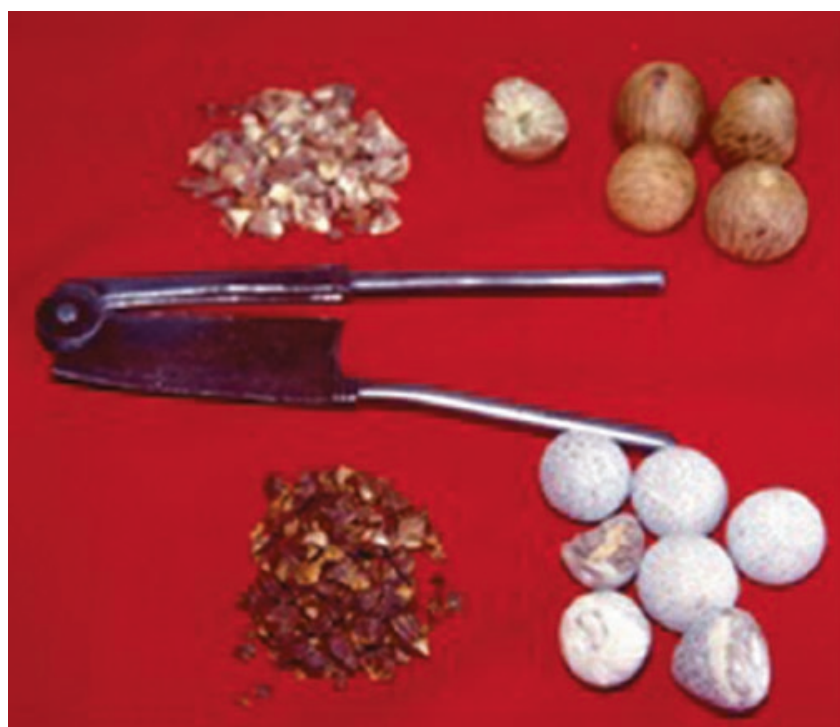

CAssociation of Oral and Maxillofacial Surgeons of India

Fig. 81.1 Betel nut (areca nut). Various forms. Raw red in color and roasted white in color. It is broken in pieces with a special cutting device. Pieces are chewed with tobacco-lime mixture or with betel quid (pan)

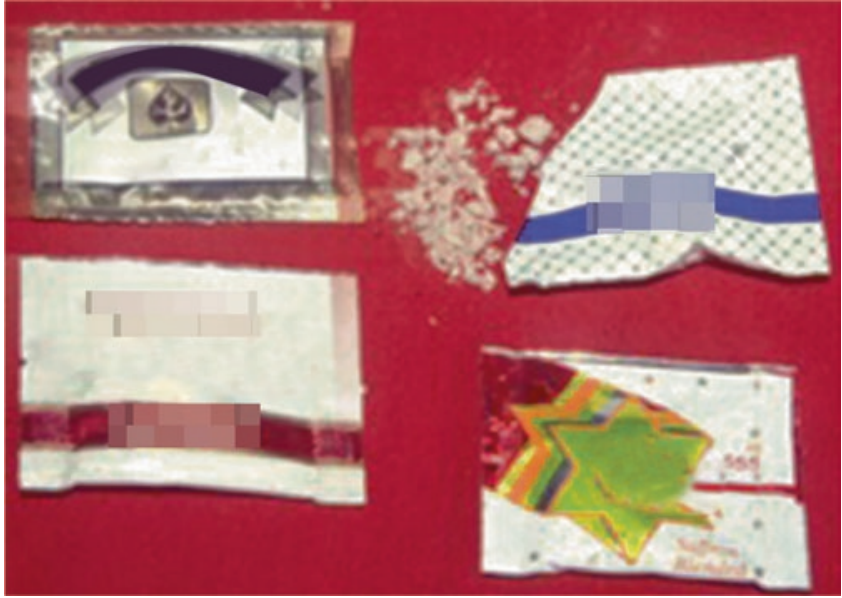

CAssociation of Oral and Maxillofacial Surgeons of India

Fig. 81.2 Pan masala (gutkha) pouches. Ready to eat mixture of tobacco, betel nut, lime, catechu, and unknown chemical coloring and flavoring agents

2. Alcohol-Alcohol is considered to be causally associated with oral cancer. As heavy alcohol drinkers are frequently heavy smokers as well, a synergistic effect with cigarette smoking is implicated in oral cancer [6-8]. Excess alcohol consumption is associated with nutritional deficiencies. This acts as an aggravating factor.

3. Betel nut chewing (areca nut)—Chronic chewing of the betel nut leads to abnormal fibrosis of the oral-pharyngeal areas. Betel nut is the endosperm of the fruit of Areca catechu. It is consumed in various forms. It is used fresh

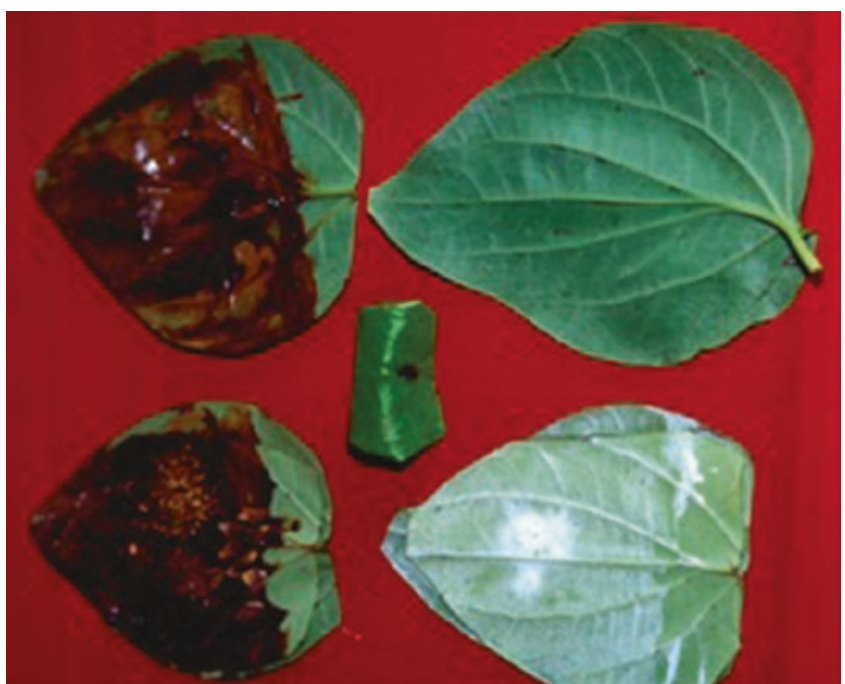

CAssociation of Oral and Maxillofacial Surgeons of India

Fig. 81.3 Pan-betel quid. Betel leaf coated with lime-catechu-flavored tobacco-betel nut. It is rolled, wrapped, and pinned with clove. Most commonly chewed in Indian subcontinent

or dried or may be cured before use by boiling, baking, or roasting. The abrasive mechanical property causes attrition of teeth and physical damage to the mucosa. This sandpaper action makes the mucosa more susceptible to the chemical properties of beetle nut. In India alone 38 different combinations of areca nut with tobacco have been documented (Fig. 81.1). The number of patients with a pan masala chewing habit $(68.0 \%)$ was higher than the number of patients with betel nut $(17.4 \%)$ or betel quid chewing habits (14.6\%). The chewing of pan masala is associated with earlier presentation of oral submucous fibrosis (OSMF) as compared to betel nut chewing [9]. Pan masala (Fig. 81.2) is the artificial mixture available in small pouches having contents of tobacco, betel nut, spices, coloring and flavoring agents, preservatives, as well as unspecified agents. This has proven to be highly carcinogenic. Consumption of this mixtures leads to OSMF which is a precancerous condition. Development of precancerous lesions like leukoplakia in preexisting fibrosis potentiates carcinoma conversion. Betel nut is also consumed with a pan (Fig. 81.3) a freshly prepared mixture on the betel leaf with tobacco, slaked lime, catechu, and clove. This is chewed over a longer time and remains in contact with oral mucosa causing mechanical and chemical irritation. The important flavonoid components in areca nut are tannins and catechins. These alkaloids undergo nitrosation and give rise to $\mathrm{N}$-nitrosamine which might have cytotoxic effect on cells [10].

4. Nutritional deficiencies-Dietary deficiencies of vitamin A, folate, riboflavin, iodine, and iron add to the risk of cancer. High dietary fiber; vitamins C, E, and A; and selenium offer protection against cancer $[11,12]$. 
5. Poor oral hygiene and traumatic injury of dental origin-Poor oral hygiene is often associated with gingivoperiodontal infections raising bacterial colony count leading to a constant inflammatory response. This together with traumatic tooth injury can lead to a carcinogenic effect.

6. Viral infections-The role of human papillomavirus (HPV) in pharyngeal cancer is well established. However its effect on the oral cavity is still being researched. Globally, HPV infection is relatively more common in OSCC patients [12].

\subsection{Precancerous Situations of Oral Cavity}

Precancerous situations can be broadly divided into precancerous conditions and precancerous lesions. Precancerous condition's most commonly seen in India are oral submucous fibrosis (OSMF) and oral lichen planus. Precancerous conditions can be associated with the precancerous lesions (please also see Chap. 80 on premalignant lesions and conditions).

\subsubsection{Precancerous Conditions}

Precancerous conditions make every part of the oral cavity susceptible to cancer conversion as is seen in oral submucous fibrosis (OSMF). The phenomenon simulates field cancerization. Development of a second primary despite adequate treatment of the first is common. Sometimes two primaries at distant anatomical sites are noted in extensive long-standing OSMF.

\subsubsection{Oral Submucous Fibrosis (OSMF)}

Oral submucous fibrosis is a chronic insidious disease of the oral mucosa characterized by loss of mucosal elasticity and excessive fibrosis (Figs. 81.4, 81.581 .6 and 81.7). It is always associated with juxta-epithelial inflammation and progressive hyalinization of lamina propria [13]. Oral submucous fibrosis (OSMF) is predominantly seen among betel quid chewers and pan masala chewers in India. OSMF generally starts at the RMT (retromolar trigone), anterior faucial pillars, and the adjoining area of the soft palate. It extends to involve the buccal mucosa, commissure, lips, and rima oris. Resulting trismus is due to mucosal and muscle fibrosis in the masseter and pterygoids. Figures 81.8 and 81.9 shows the traumatic ulcers caused in buccal mucosa and RMT area in OSMF cases mainly due to the limited mouth opening and fibrosis. In such cases early dental intervention or extractions

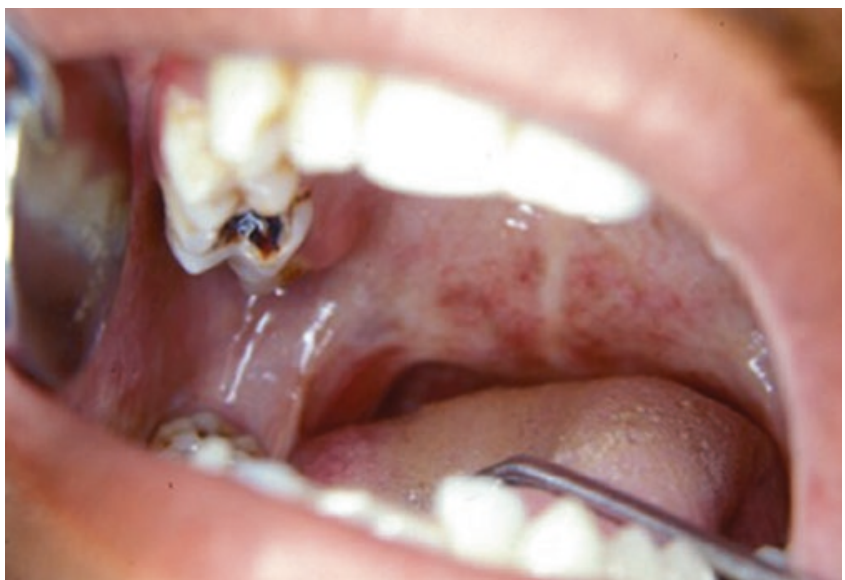

CAssociation of Oral and Maxillofacial Surgeons of India

Fig. 81.4 OSMF (oral submucous fibrosis). Note fibrosis affecting RMT, faucial pillars, buccal mucosa, as well as rima oris

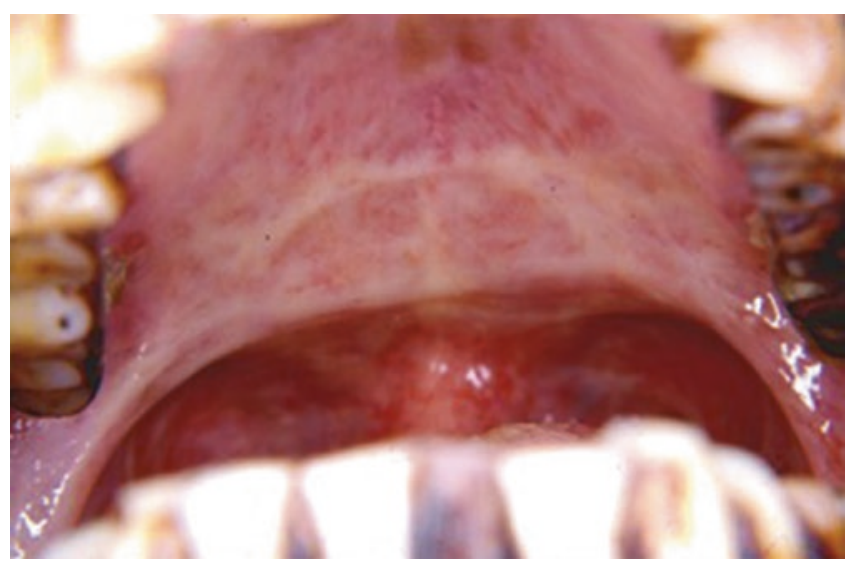

CAssociation of Oral and Maxillofacial Surgeons of India

Fig. 81.5 OSMF (oral submucous fibrosis). Note fibrosis affecting RMT, faucial pillars

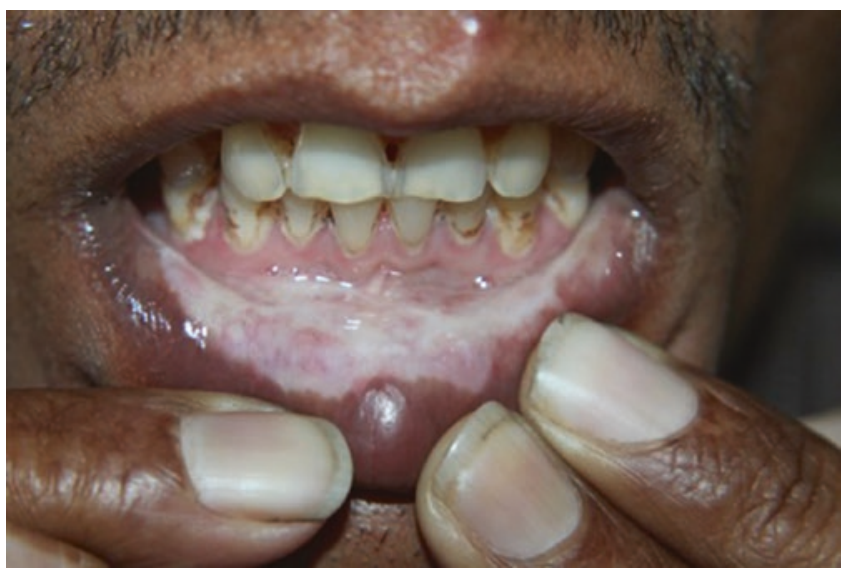

CAssociation of Oral and Maxillofacial Surgeons of India

Fig. 81.6 OSMF (oral submucous fibrosis). Note fibrosis affecting lower lip and blanching of mucosa. Note pale nails due to anemia 


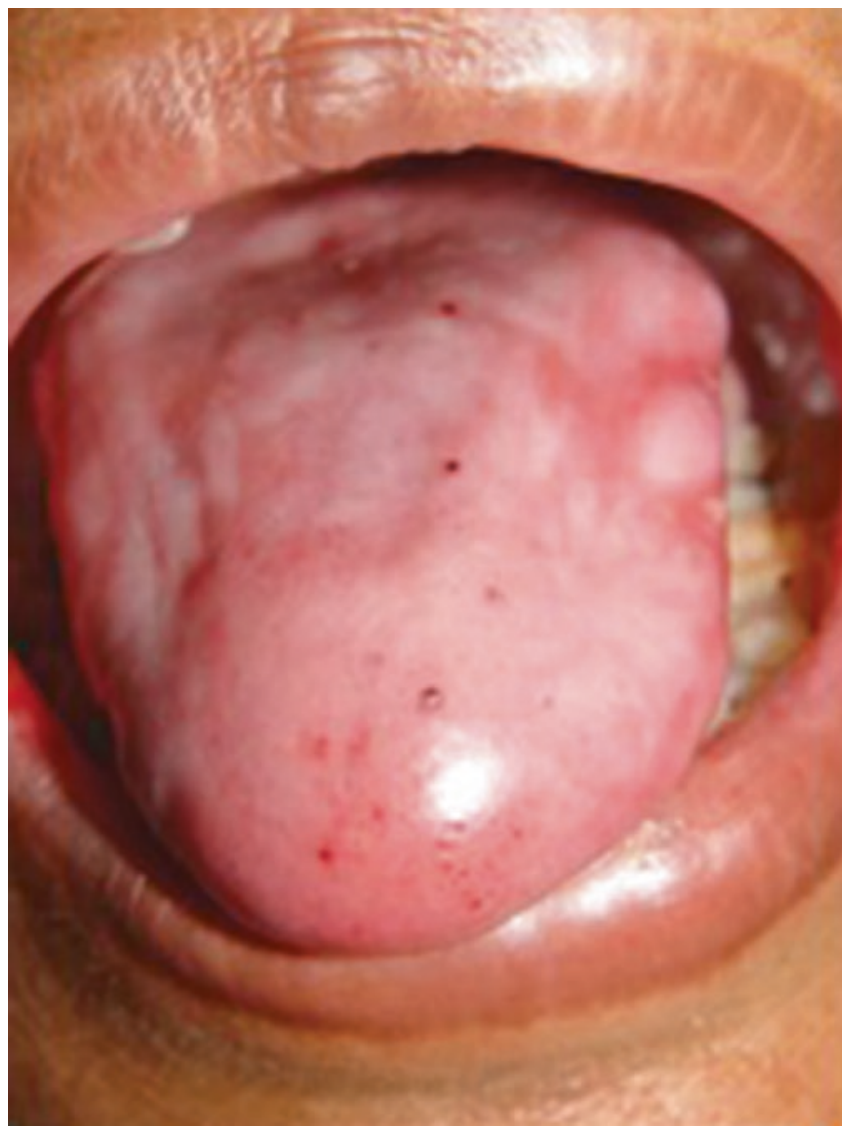

(C)Association of Oral and Maxillofacial Surgeons of India

Fig. 81.7 Bald tongue in OSMF. Has high malignant potential

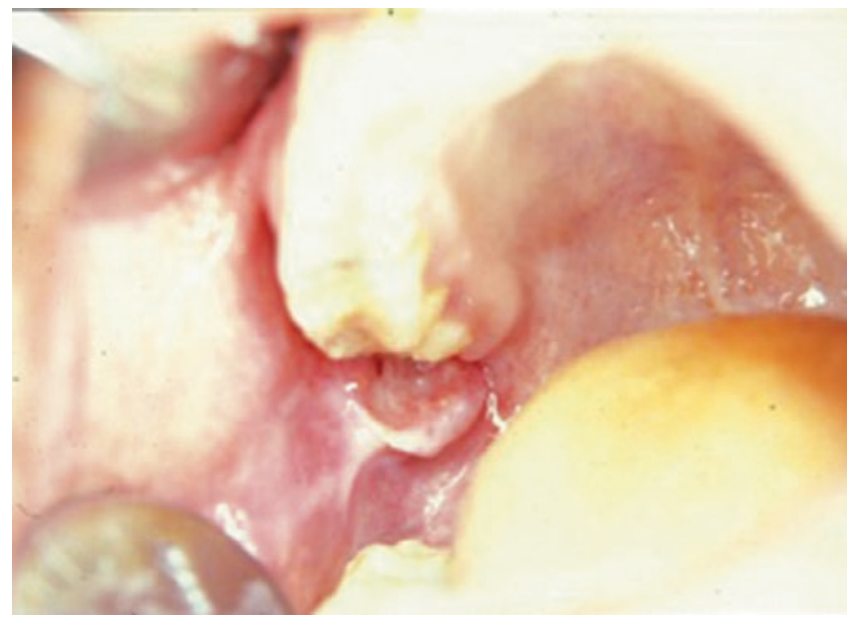

CAssociation of Oral and Maxillofacial Surgeons of India

Fig. 81.8 OSMF with traumatic ulceration from last molars

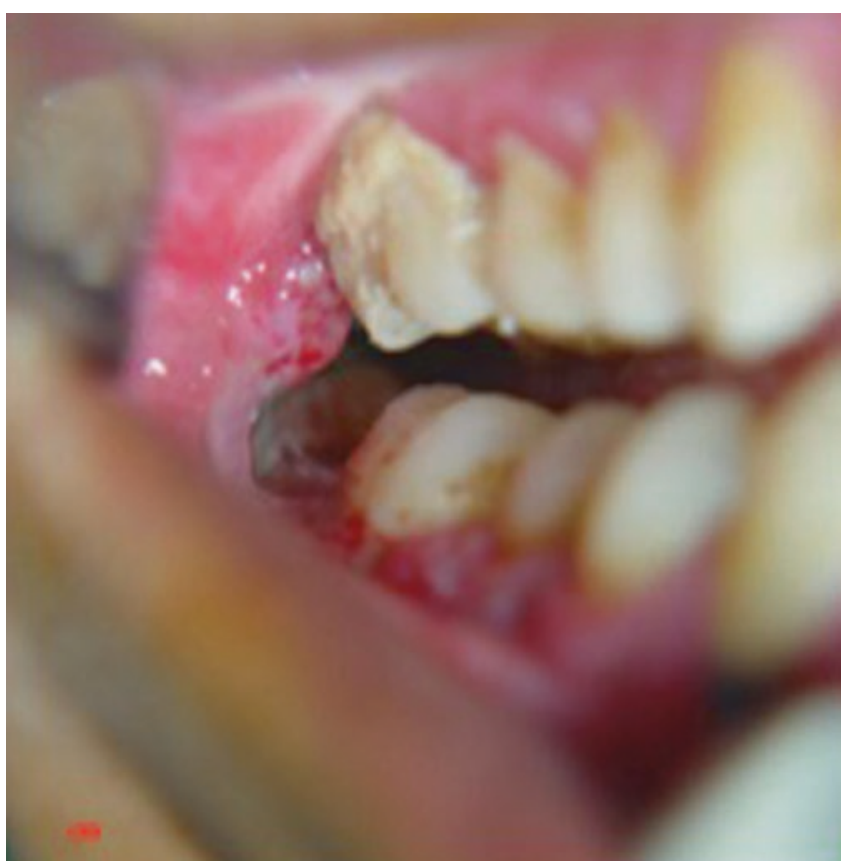

CAssociation of Oral and Maxillofacial Surgeons of India

Fig. 81.9 OSMF with traumatic ulceration from last molars

may be delayed due to the difficulty in access to the posterior teeth due to trismus. Such chronic traumatic ulceration may undergo malignant change as seen in Fig. 81.10.

\subsubsection{Molecular Pathogenesis of OSMF}

Time and constant irritation lead to inflammation with mucosal atrophy. It can thus be considered that induction of oral mucosal inflammation by betel quid is a critical event in the pathogenesis of OSMF. Cytokines like interleukin-6 (IL-6), tumor necrosis factor (TNF), interferon-a (INF-a), and growth factors like TGF-b are synthesized at the site of inflammation.

TGF-b1 is a key regulator of extracellular matrix (ECM) assembly and remodeling. TGF-b1 increases collagen production and decreases its degradation [14]. OSMF has characteristic clinical presentation depending on the stage of the disease. The majority of patients have intolerance to spicy food, roughness of oral mucosa, and varying degrees of difficulty in opening the mouth.

OSMF is a well-recognized potentially premalignant condition of the oral cavity. The transformation rate is as high as $7.6 \%$ over a period of 10 years [15]. In this group, primary malignancy develops in the buccal mucosa extending to involve the retromolar trigone. This is unique in the context 


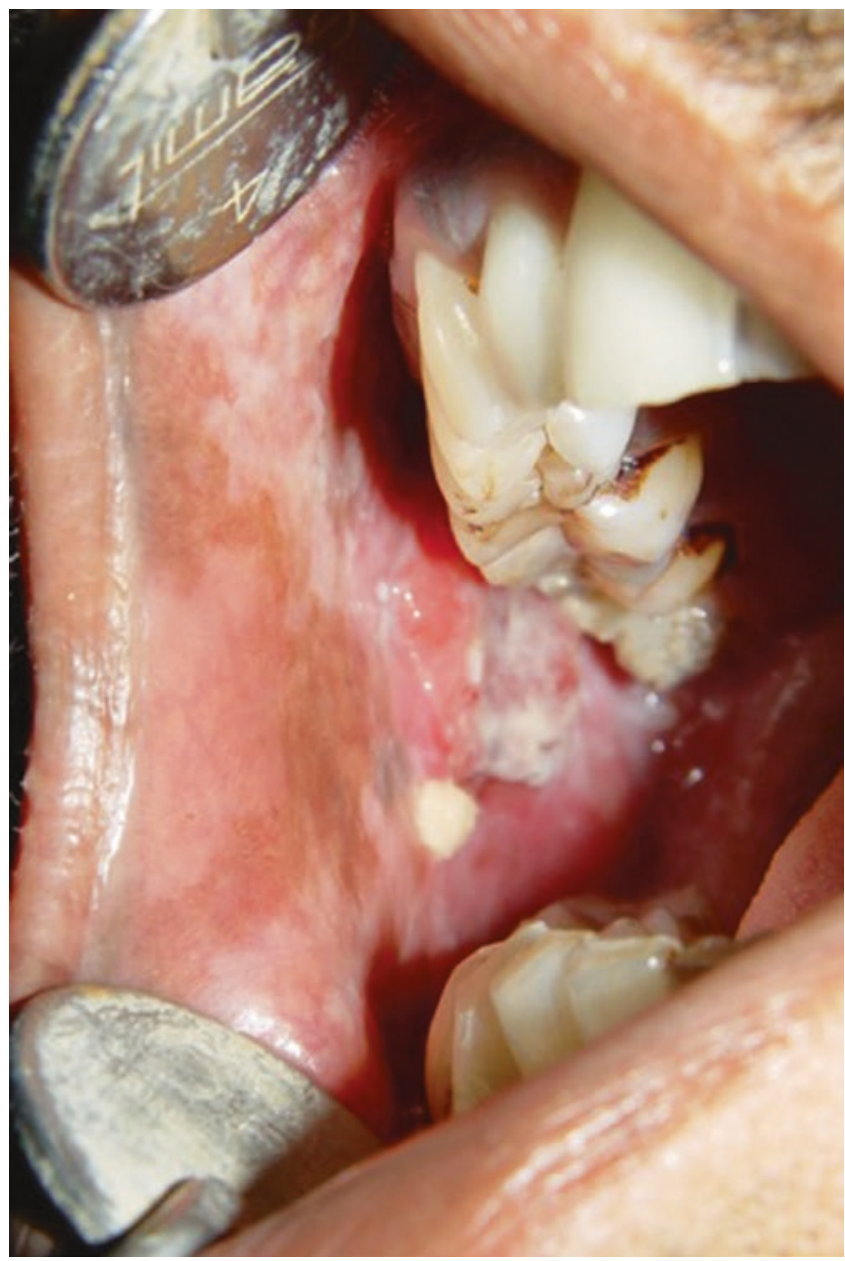

CAssociation of Oral and Maxillofacial Surgeons of India

Fig. 81.10 Malignant transformation in posterior buccal mucosa in a case of OSMF, accompanied by chronic trauma form tooth

of the Indian subcontinent, as pure tobacco chewing habit has decreased and is replaced by the gutkha chewing habit. Tobacco-lime preparation used to be kept in the GBS or the floor of the mouth for longer period. This led to leukoplakia and/or erythroplakia, followed by malignant transformation. The current preparation is not constantly placed in the GBS but chewed for long time and swallowed. The chemical effect leads to OSMF and field concretization.

\subsubsection{Oral Lichen Planus}

Oral lichen planus (OLP) tends to often present bilaterally as white striae on the buccal mucosa. Any mucosal site in the mouth may be involved. Other sites, in decreasing order of frequency, may include the tongue, lips, gingivae, floor of the mouth, and very rarely palate [16].

Six clinical forms of oral lichen planus are recognized [17]: reticular, erosive/ulcerative, papular, plaque-like, atrophic, and bullous. Atrophic/erosive lichen planus is associated with a risk of cancerous transformation [18]. Patients with OLP tend to be monitored closely to detect any potential change early.

The rate of malignant transformation in individual studies ranged from 0 to $3.5 \%$. The overall rate of transformation was $1.09 \%$ for OLP.

\subsubsection{Precancerous Lesions}

Precancerous lesion is a pathology of the oral mucosa which has a tendency to transform into the squamous cell carcinoma. The commonly prevalent lesions are leukoplakia erythroplakia, carcinoma in situ, and smoker's palate.

\subsection{Diagnosis of Oral Squamous Cell Carcinoma (OSCC)}

Diagnosis of oral squamous cell carcinoma is not a challenging task except in the cases of an unknown primary. History of risk factors, classic clinical appearance of an indurated ulcer, involvement of lymph nodes, and destruction of bone are common features in advanced disease.

\subsubsection{Clinical Features of Oral Carcinoma}

Oral squamous cell carcinoma often presents as an indurated ulcer, exophytic growth, indurated non-ulcerative patch (endophytic), or a combination of the above appearances. Figures $81.11,81.12,81.13,81.14,81.15,81.16,81.17$, and 81.18 shows the various clinical presentation of SCC in tongue. Fig. 81.19 shows multiple primary tumors arising in case of OSMF.

Important parameters to be recorded at the primary site in clinical examination are site of the tumor; size; extension to involve adjacent structures like the skin, muscles, bone of maxilla and/or mandible, and skull base; and extensions into compartments such as the paranasal sinuses, nasal cavity, orbit, pterygoid space, masticatory compartment, and infratemporal fossa. Regional spread to the lymph node basin in the neck needs clinical and radiologic correlation. Evaluation of distant metastasis to lungs and bones forms a part of the staging process. 


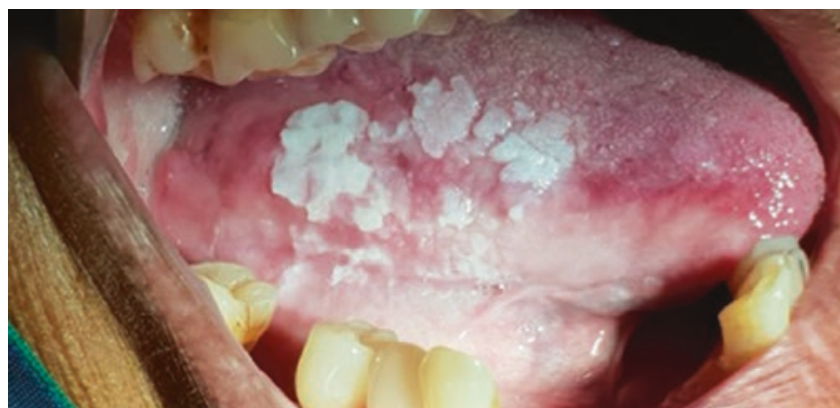

CAssociation of Oral and Maxillofacial Surgeons of India

Fig. 81.11 Precancerous lesion of the tongue-diffuse leukoplakia. Lesion has a potential to undergo SCC

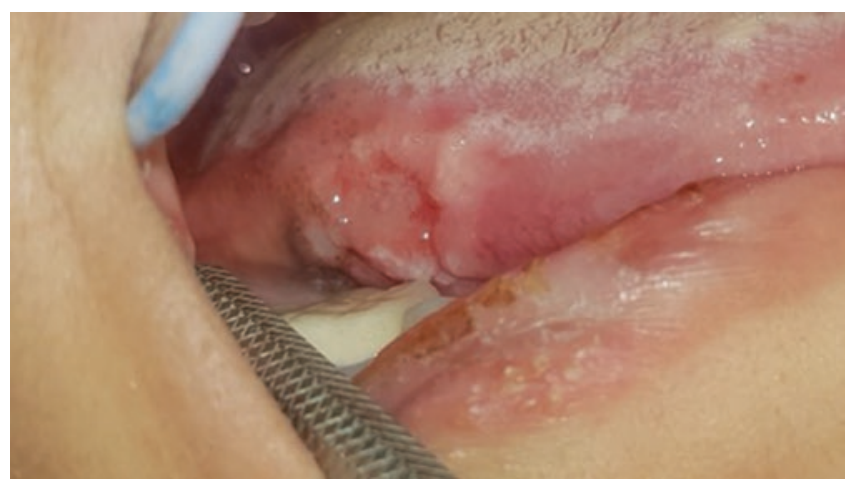

CAssociation of Oral and Maxillofacial Surgeons of India

Fig. 81.12 OSCC of the tongue-inverted margins. Lesion not associated with any habit. These lesions often can have genetic predilection and behave aggressively

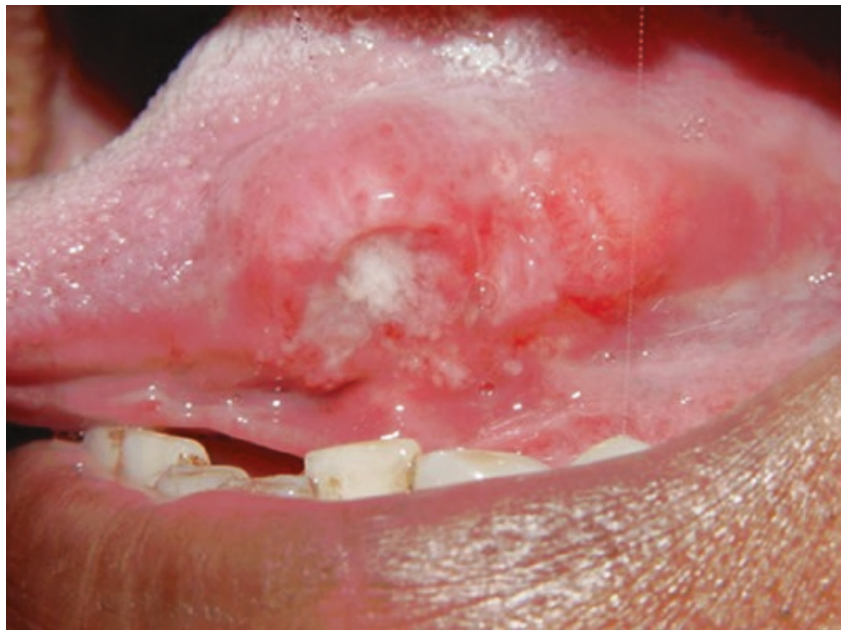

CAssociation of Oral and Maxillofacial Surgeons of India

Fig. 81.13 OSCC of the tongue - everted margins. Lesion can behave aggressively often associated with tobacco-related habit

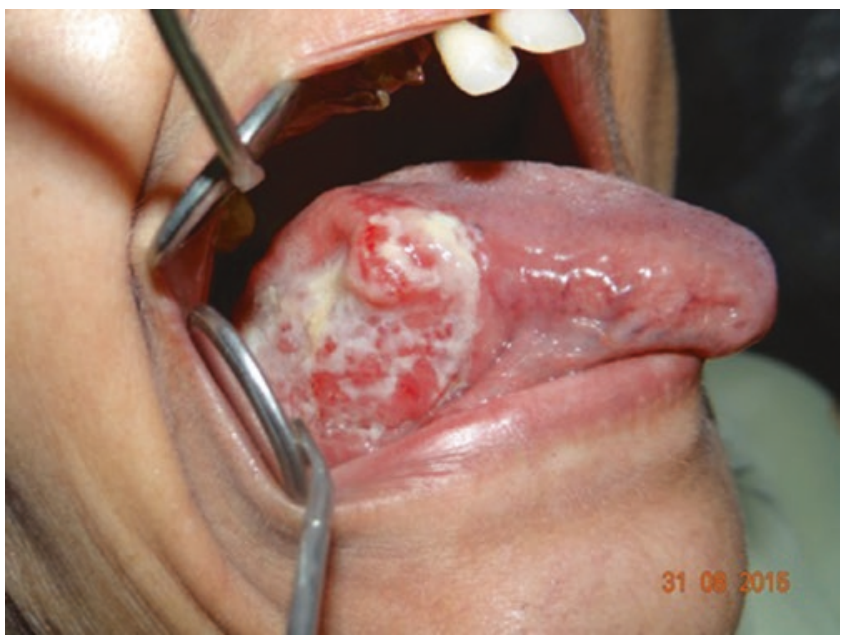

CAssociation of Oral and Maxillofacial Surgeons of India

Fig. 81.14 OSCC of the tongue-exophytic growth. Lesions have nonaggressive behavior with better prognosis

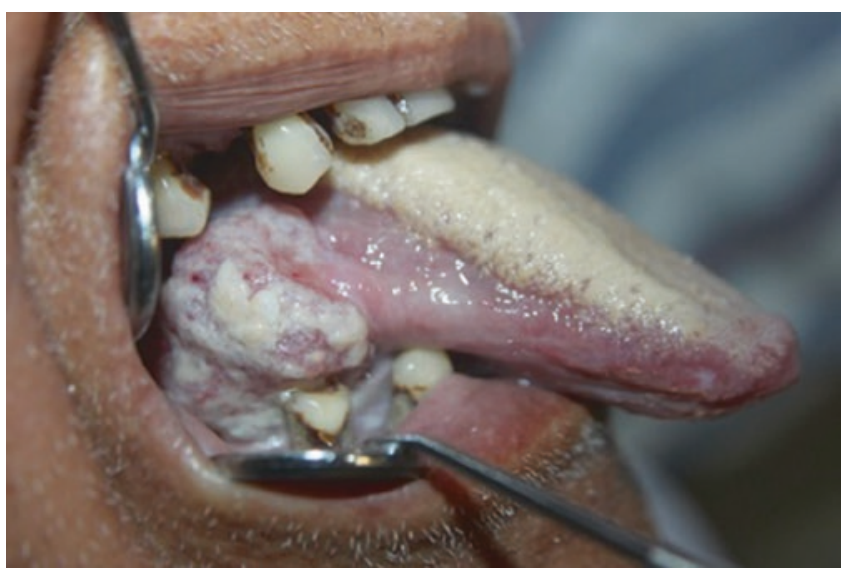

CAssociation of Oral and Maxillofacial Surgeons of India

Fig. 81.15 Another case of OSCC of the tongue-exophytic growth. Lesions have nonaggressive behavior with better prognosis

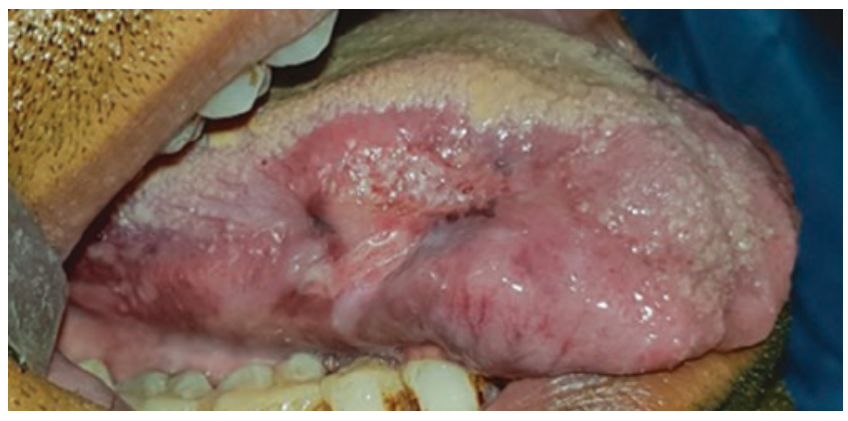

CAssociation of Oral and Maxillofacial Surgeons of India

Fig. 81.16 OSCC of the tongue-ulcerative patch. Lesion is not associated with any habit. Genetic predilection 


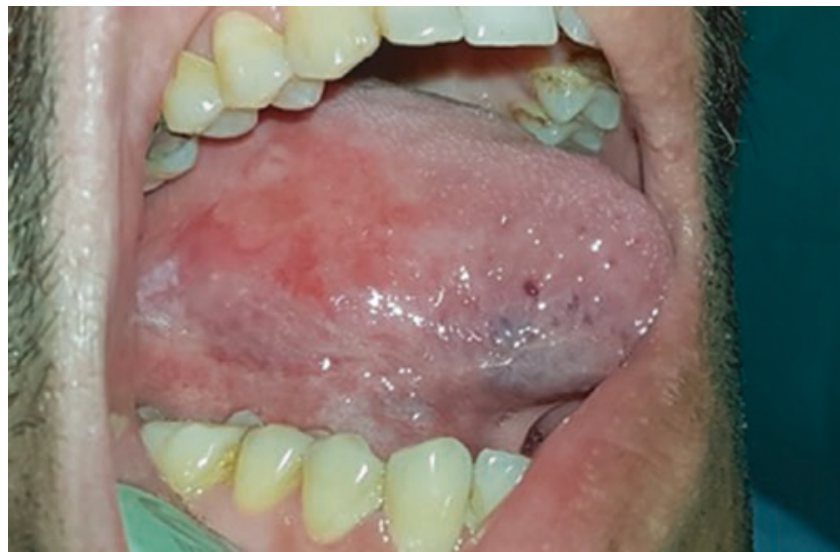

CAssociation of Oral and Maxillofacial Surgeons of India

Fig. 81.17 OSCC of the tongue-non-ulcerative patch. Lesion is frequently associated with smoking

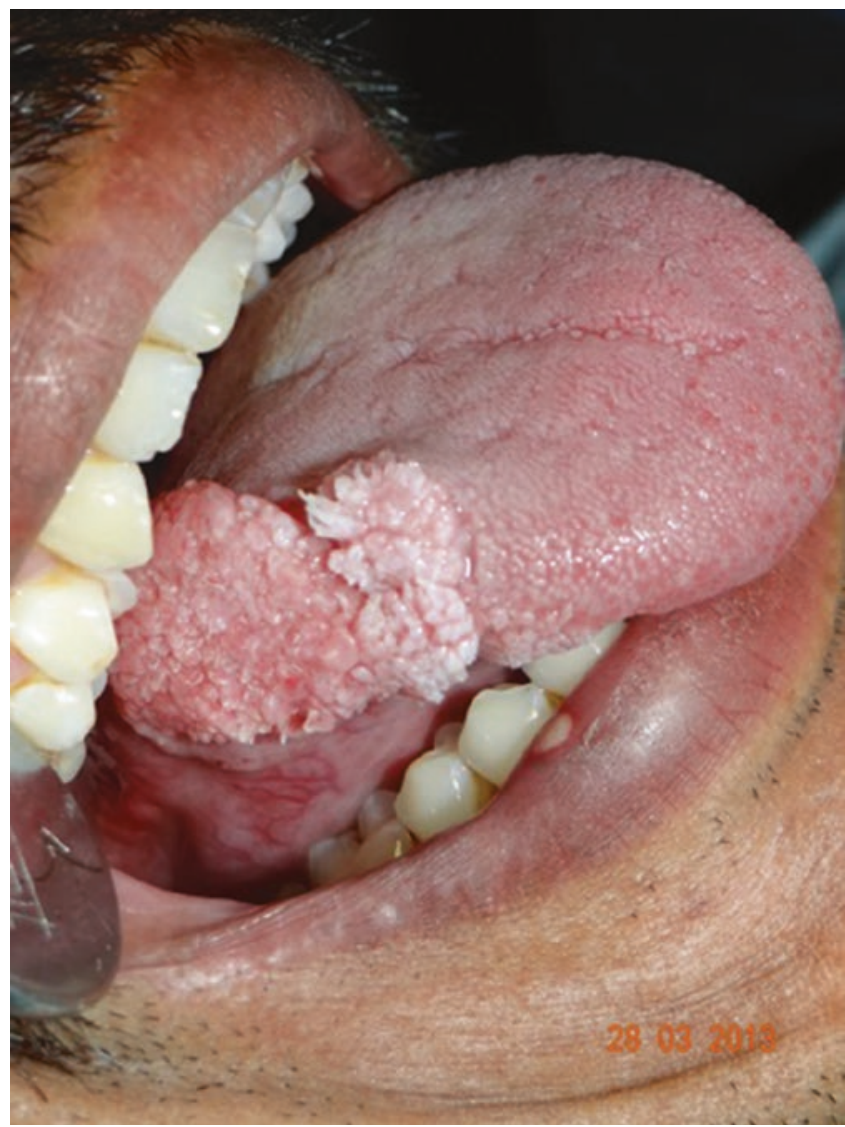

CAssociation of Oral and Maxillofacial Surgeons of India

Fig. 81.18 OSCC of the tongue-verrucous growth. Lesion generally has dormant behavior with better prognosis

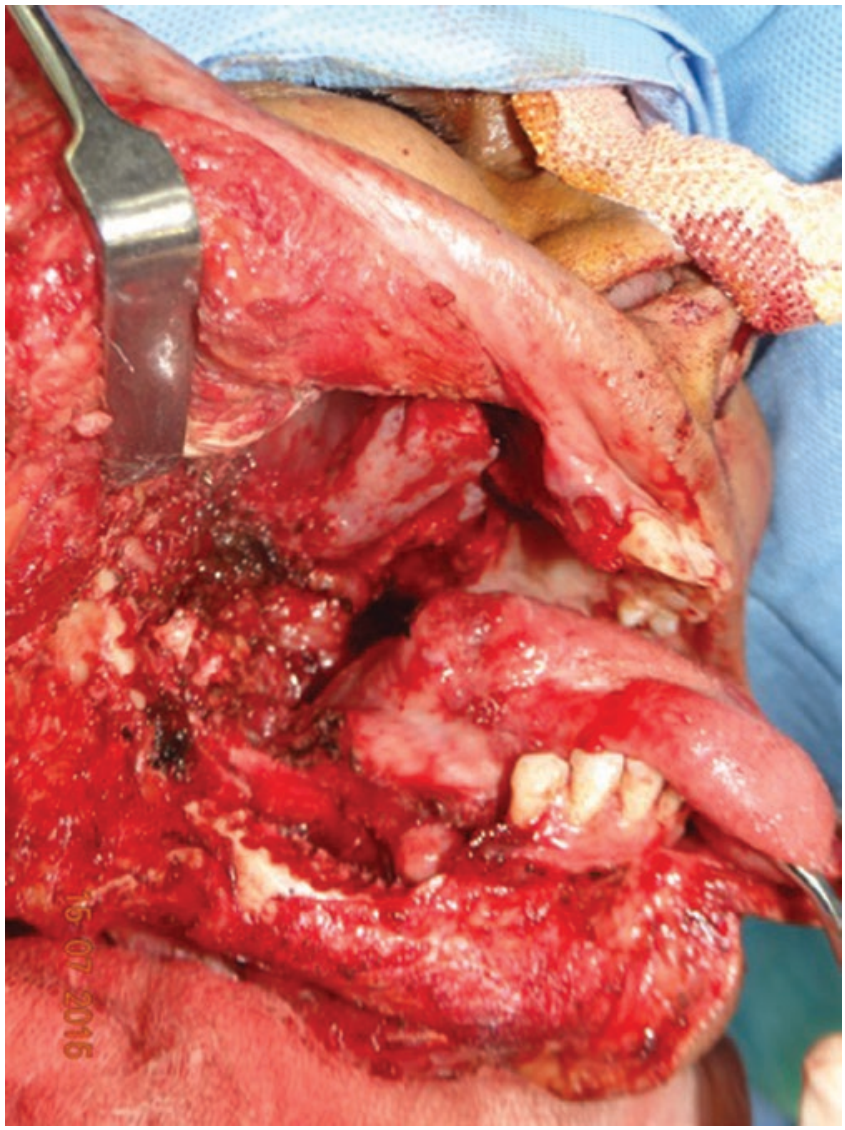

Fig. 81.19 Intraoperative picture. Multiple primary tumors-SCC in OSMF. Rt.GBS/BM — resected, with Tongue-Rt. side. Either of these can be considered as Second Primary Tumour (SPT)

\subsection{Imaging in OSCC Diagnosis}

The minimum radiologic investigation for the primary site and neck should include imaging from the skull base to the clavicle. Staging of the chest is to detect both metastatic disease and synchronous tumors. MRI and/or CT with contrast is considered to be the gold standard. In poorer socioeconomic background, one could consider ultrasound scan of the neck as a staging modality. This will however not adhere to the current international guidelines. In our units the minimum standard is a MRI of the neck (including the primary) and CT chest. A double-contrast CT of the neck is as valuable as a MRI. Radiologic examination provides a greater accuracy in the staging process. Prognosticators such as depth of invasion and extracapsular spread in lymph nodes can be studied with good accuracy.

Where there is involvement of bone, a MRI and CT will provide better definition for resection. Marrow signal changes can only be evaluated on a MRI. The CT provides 
Fig. 81.20 PET-CT-SCCContralateral neck metastasis, at IIA, of second primary in Lt. Maxilla

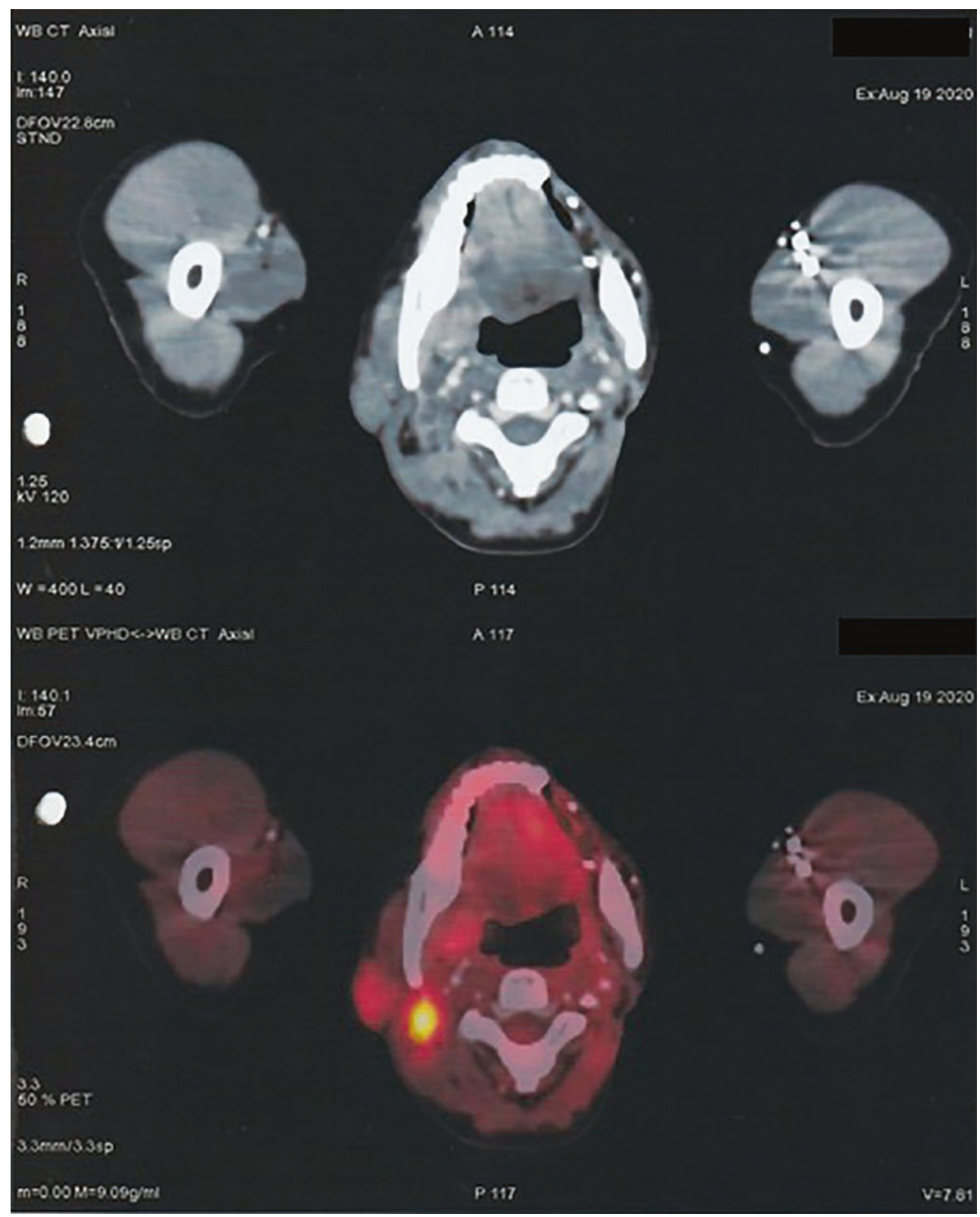

CAssociation of Oral and Maxillofacial Surgeons of India better information on cortical erosion. In addition a thin slice CT helps in 3D planning prior to free flap reconstruction.

The role of a PET-CT is limited. Its primary indication is to detect an unknown primary prior to targeted biopsy. A further role for the PET-CT is in post-radiotherapy evaluation of the neck (Fig. 81.20).

MRI scans offer better accuracy of soft tissue extension of tumor. Studying fat planes between muscle groups allows for compartment resections in $\mathrm{T} 4$ tumors.

\subsection{Tissue Sampling}

Incisional biopsy is the gold standard in the diagnosis of squamous cell carcinoma. FNAC is used for the detection of lymph node metastasis. However with the increased accuracy in MRI and USS reporting, this modality is used less. Biopsy tissue should be taken from the most indurated portion of the tumor. Taking a biopsy from the summit or the center of an ulcer may yield a false-negative result. Scalpel, punch, and low-voltage electrocautery are all good options. Minimum size of the sampled tissue should be ideally $6 \mathrm{~mm}$ in all three dimensions. Mapping biopsy from multiple sites may be required at times to evaluate the extent of involvement and to prevent a falsenegative result. This is especially the case when a tumor develops in the background of a premalignant lesion.

Deep biopsy is required to get estimation on the depth of invasion (DOI). In cases of exophytic lesions, tumor thickness may cause difficulty in getting deeper tissue; in such cases tumor margin area can be chosen. In order to obtain a good-quality oral biopsy, the clinician should avoid crushing the sample with the tissue-holding forceps, infiltrating anes- 
thetic solution within the lesion, using an insufficient volume of fixing solution and taking insufficient amount of tissue in extension and depth. The specimen should be handled gently, avoiding any crushing, and introduced in the fixing solution such as $10 \%$ formalin.

In inaccessible areas, due to the site of tumor or reduced mouth opening, it is good practice to carry out an examination under anesthesia to evaluate the extent of the tumor. This also provides an opportunity for the lesion to be accurately biopsied in a more controlled environment of theaters.

\subsubsection{Histopathology}

Pathologist is expected to report on the tumor grade-welldifferentiated squamous cell carcinoma, Grade 1; moderately differentiated squamous cell carcinoma, Grade 2; or poorly differentiated squamous cell carcinoma, Grade 3 . Well-differentiated tumors resemble normal squamous epithelium to a large degree (Fig. 81.21), poorly differentiated tumors exhibiting little or no histologic traits of the squamous phenotype, and moderately differentiated tumors having an intermediate morphology between the two ends of the spectrum. Higher grades have strong potential for recurrence and lymph node metastasis [19].

Several prognostic indicators have consistently demonstrated a correlation with disease-specific survival, local and regional recurrence, and lymph node metastasis in numerous single or multicenter studies. The prognosticators are depth of invasion (DOI), pattern of invasion (POI), perineural invasion (PNI), lymphovascular invasion (LVI), and extranodal extension (ENE).

\subsubsection{Depth of Invasion/Tumor Thickness}

It is important to differentiate between depth of invasion and tumor thickness. The DOI is a more predictable prognostica-

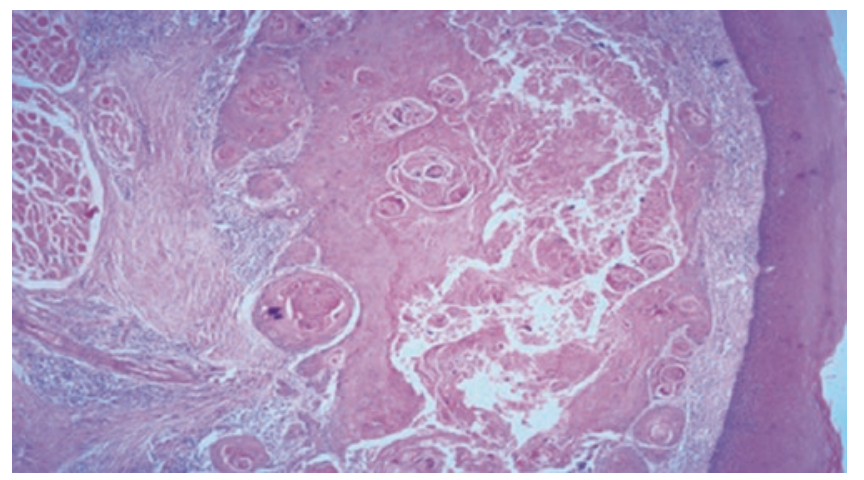

CAssociation of Oral and Maxillofacial Surgeons of India

Fig. 81.21 Well-differentiated OSCC. H\&E 10x tor compared to the latter. It is known that exophytic tumors (verrucous carcinomas being the prototype) or predominantly exophytic tumors have a good prognosis, whereas endophytic or deeply infiltrating tumors are aggressive [20]. Depth of invasion (DOI) is an important independent factor in prognosis with strong effect on disease-free survival and overall survival, correlating with propensity for nodal spread better than tumor size in oral cancer [21-25]. In the floor of the mouth, 1-cm-wide tumor infiltrating at $0.7 \mathrm{~cm}$ depth will likely have a worse outcome and carries a higher risk of neck metastasis than a 2-cm-wide tumor with microinvasion or superficial invasion (e.g., less than $2 \mathrm{~mm}$ in thickness) [26-28].

\subsubsection{Pattern of Invasion}

Pattern of tumor invasion is an important prognostic factor. Tumor interface abutting deeper tissues has better prognostic value as compared to multiple tumor satellites into the deeper tissues [20].

\subsubsection{Perineural Invasion (PNI)}

PNI presence is a soft indicator for local recurrence and decreased survival. Multiple studies have shown conflicting results [29]. However it is one of the most important predictors of neck metastasis [30] alongside DOI. PNI increases the rate of occult metastasis [31].

\subsubsection{Lymphovascular Invasion (LVI)}

Histopathological presence of lymphovascular invasion has poorer prognostic outcome. The presence of LVI is associated with nodal spread or occult metastases [23, 32-34]. Literature review has conflicting evidence regarding the importance of LVI.

\subsubsection{Bone Invasion}

It is common to see OSCC of GBS and retromolar trigone (RMT) invade the adjoining mandible, maxilla, and pterygoid column. This upstages the tumor to a T4.

The increased risk of local recurrence can be attributed to two factors-tumor character and margin status following resection. Invasion into the pterygoid spaces makes surgical resection difficult. Close margin is expected in these advanced tumors.

Mandible infiltration can be of periosteal fixation, cortical erosion, or medullary invasion. Deeper invasion has poor prognosis [35] (Fig. 81.22). 


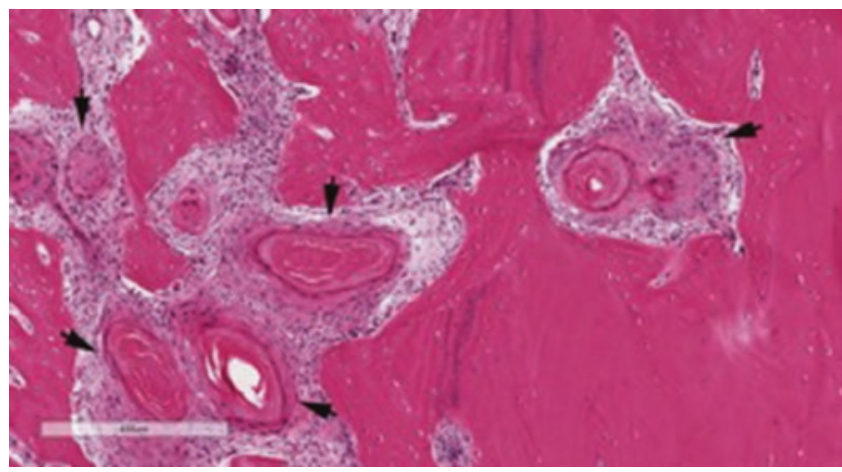

CAssociation of Oral and Maxillofacial Surgeons of India

Fig. 81.22 OSCC with bone invasion. H\&E 10X

\subsection{Neck Assessment in OSCC}

A positive neck node is the single most important prognosticator for disease-free survival at 5 years. Size, number of levels involved, fixation to adjacent structures, and extranodal extensions (ENE) are of significance in lymph node assessment of the neck.

In a N0 neck, the pickup rate of a sub-centimeter positive node is less than $50 \%$ on clinical examination alone. Use of radiologic examination increases the pickup rate to $90 \%$. A staging neck dissection is the only modality that has a pickup rate greater than $98 \%$ [36-38].

A well-lateralized tumor often spreads to the ipsilateral neck. In $5 \%$ of patients, the first echelon can be the contralateral neck. Tongue cancers have the propensity for skip metastasis and contralateral spread. For all other regions of the oral cavity, the first echelon spread is at level I/II.

Depending on the literature one reads, the specificity and sensitivity between MRI and CT are confusing. The authors recommend that the radiologist choose the modality he has the greatest confidence in reporting. Ultrasound scan as a screening tool is useful in the outpatient setting.

Radiologic signs of nodal involvement are increases in size of the lymph node, obliteration of the fatty hilum, increased vascularity, an ill-defined outline, and intranodal necrosis. Ten millimeters or more in an axial section are considered positive for nodal involvement in the neck. However, false-positive or false-negative results of $15-20 \%$ are noted in the literature $[39,40]$.

\subsection{Distant Metastasis}

Distant metastasis needs to be suspected in lungs and vertebrae. Evaluation is done by CT alone or a PET-CT scan.

\subsection{TNM Staging System}

Cancer staging can be divided into a clinical stage and a pathologic stage. In the TNM (Tumor, Node, and Metastasis) system, clinical stage and pathologic stage are denoted by a small "c" or "p" before the stage (e.g., cT3N1M0 or pT2N0). This staging system is used for most forms of cancer. Accurate staging is critical as treatment is often based on clinical and radiologic stage.

Currently AJCC eighth Edition is used; this includes both the depth of primary tumor invasion and extracapsular extension of lymph node metastases. The AJCC eighth Edition OSCC staging system showed improved disease-free survival discrimination between overall stages and between $\mathrm{T}$ categories, while AJCC seventh Edition did not [19].

\subsubsection{AJCC Eighth Edition Clinical Staging System}

T-Primary tumor.

Tx-Primary tumor cannot be assessed.

Tis-Carcinoma in situ.

T1-Tumor $\leq 2 \mathrm{~cm}$ in greatest dimension, $\leq 5 \mathrm{~mm}$ depth of invasion (DOI not tumor thickness).

T2-Tumor $\leq 2 \mathrm{~cm}$ with DOI $>5 \mathrm{~mm}$ or tumor $>2 \mathrm{~cm}$ and $\leq 4 \mathrm{~cm}$ with $\mathrm{DOI} \leq 10 \mathrm{~mm}$.

T3-Tumor $>2 \mathrm{~cm}$ and $\leq 4 \mathrm{~cm}$ with DOI $>10 \mathrm{~mm}$ or tumor $>4 \mathrm{~cm}$ with $\mathrm{DOI} \leq 10 \mathrm{~mm}$.

T4-Moderately advanced or very advanced local disease.

T4a-Moderately advanced local disease.

Lip: tumor invades through cortical bone or involves the inferior alveolar nerve, floor of the mouth, or skin of the face (i.e., chin or nose).

Oral cavity: tumor invades adjacent structures only (e.g., through cortical bone of the mandible or maxilla, or involves the maxillary sinus or skin of the face). Note: Superficial erosion of bone/tooth socket (alone) by a gingival primary is not sufficient to classify a tumor as T4.

T4b-Very advanced local disease. Tumor invades masticator space, pterygoid plates, or skull base and/or encases internal carotid artery.

Regional lymph nodes (N) ENE-extranodal extension.

$\mathrm{Nx}$-Regional lymph nodes cannot be assessed.

N0-No regional lymph node metastasis.

N1-Metastasis in a single ipsilateral lymph node, $\leq$ $3 \mathrm{~cm}$ in greatest dimension and ENE (-).

$\mathrm{N} 2-$ Metastasis in a single ipsilateral lymph node, $>3 \mathrm{~cm}$ but $\leq 6 \mathrm{~cm}$ in greatest dimension and ENE (-); or mets in multiple ipsilateral lymph nodes, $\leq 6 \mathrm{~cm}$ in greatest dimen- 
Table 81.1 AJCC prognostic staging groups according to the eighth AJCC edition

\begin{tabular}{ll|l|l|} 
Clinical group & T & N & M \\
\hline 0 & Tis & N0 & M0 \\
I & T1 & N0 & MO \\
II & T2 & N0 & MO \\
III & T3 & N0 & MO \\
& T1 T2 T3 & N1 & MO \\
IVA & T4a & N0 & MO \\
& T1T2T3T4a & N1, N2 & M0 \\
IVB & T4b & Any N & MO \\
& Any T & N3 & M0 \\
IVC & Any T & Any N & M1
\end{tabular}

sion and ENE (-); or mets in bilateral or contralateral lymph nodes, $\leq 6 \mathrm{~cm}$ in greatest dimension and ENE (-).

N2a-Metastasis in single ipsilateral lymph node $>3 \mathrm{~cm}$ but $\leq 6 \mathrm{~cm}$ in greatest dimension and ENE (-).

$\mathrm{N} 2 \mathrm{~b}-$ Metastasis in multiple ipsilateral lymph nodes $\leq 6 \mathrm{~cm}$ in greatest dimension and $\operatorname{ENE~(-).~}$

$\mathrm{N} 2 \mathrm{c}-$ Metastasis in bilateral or contralateral lymph nodes $\leq 6 \mathrm{~cm}$ in greatest dimension and $\operatorname{ENE~(-).~}$

N3-Metastasis in a lymph node $>6 \mathrm{~cm}$ in greatest dimension and ENE (-) or metastasis in any lymph node(s) with clinically overt ENE (+).

N3a-Metastasis in a lymph node $>6 \mathrm{~cm}$ in greatest dimension and ENE (-).

$\mathrm{N} 3 \mathrm{~b}-$ Metastasis in any lymph node(s) with clinically overt ENE (+).

Distant metastasis $(\mathrm{M})$.

M0 - No distant metastasis (no pathologic M0; use clinical $\mathrm{M}$ to complete stage group).

M1-Distant metastasis.

AJCC prognostic stage groups are provided in Table 81.1.

\subsection{Treatment Planning for the Management of Head and Neck Malignancy}

\subsubsection{Introduction}

The management of head and neck cancer has undergone a sea change since the 1980s. The most important change that has been to the benefit of both patients and clinicians is the emphasis on evidence-based practice, and this has led to the development of the multidisciplinary team (MDT) or the tumor board as it is also known as.

In the more recent past, a new thought process is the practice of realistic medicine. The emphasis is on a more personalized approach to patient care and changing our style to shared decision-making. This is an approach that has been rolled out across Scotland.

\subsubsection{MAGIC: Making Good Decisions in Collaboration}

The key questions to be asked are:

1. Is this test, treatment, or procedure really needed?

2. What are the potential risks and benefits?

3. What are the potential side effects?

4. Are there alternative simpler, safer treatment options?

5. What would happen if one did nothing?

\subsubsection{The Start of Treatment Planning}

The beginning of planning treatment starts on the receipt of a referral or patients' attendance. Patients with a history of a neck or salivary gland lump, non-healing ulcer of the oral cavity, bleeding, pain refractory to analgesia, hoarseness, and dysphagia are seen in the clinic within 2 weeks. Clinical examination should include the examination of the tongue base, tonsils, larynx, and nasopharynx with flexible nasoendoscope.

Developing a one-stop clinic helps in avoiding delays, and this has a significant impact on patients' psychological well-being. The one-stop clinic includes a biopsy on the same day for visible lesions and an ultrasound-guided core biopsy of neck lumps. The results of these preliminary investigations should be available in a week, setting up for a second meeting.

\subsubsection{The Second Meeting}

The second meeting or breaking bad news is perhaps the most important consultation in treatment planning. Patients are invited to attend the clinic with members of their family. Consultation is held in a quiet atmosphere in the presence of a clinical nurse specialist. It is important to be factual and honest. Unrealistic expectations should not be given. One must also bear in mind the impact the diagnosis will have on patients and their families. Empathy is very important. A good rapport with the patient and their family is invaluable.

\subsubsection{Staging Scans}

The minimum staging scans for head and neck cancer include a MRI and/or CT neck and CT chest. The rationale for staging is localization of the tumor and detection of regional and 
distant lymph node metastases. This has an importance in both the extent of therapeutic intervention and the diseasespecific survival.

\subsubsection{Localization of Primary Tumor}

The localization of the primary tumor helps in the decisionmaking regarding the resectability of the lesion with clear margins. Tumor resection with a R1 margin is considered a futile procedure, and at the best it is palliative and at its worst just a "big biopsy." Anatomical areas of interest in localization are the skull base with particular interest to the carotid canal, involvement of the infratemporal fossa, the extent into the orbit, and in the case of tongue tumors proximity to the tongue base and larynx. Involvement of any of the above structure carries a very high risk of a positive or close margins resulting in increased risk of recurrence. Adjuvant treatment would then be inevitable. Functional outcomes are poorer.

MRI of the soft tissues is our preference for localization of the tumor as it helps in planning anatomic resection by determining the depth of infiltration. This can be in the form of compartment resection-medial masticatory compartment resection for retromolar, soft palate, and posterior tongue tumors. Anatomical resections in tongue tumors uses muscle planes to identify margins and vascularity of the remainder tongue. The muscle groups most important to this are the mylohyoid, styloglossus, and stylohyoid. With tumors extending to the infratemporal fossa and skull base, a key landmark is the styloid. Prestyloid resections are considered straightforward, and a R0 margin is to be expected. Tumors in the poststyloid space carry the risk of a close margin.

Tumors involving the mandible and maxilla, in our practice, have a CT and MRI. The MRI helps in determination of marrow signal change and gives an aid to planning resection margins. The CT has a two fold advantage. CT helps localize cortical breach and complements the MRI in planning resection. It has also the added advantage of obtaining 3D models which helps in planning bone reconstruction with a free flap.

For malignancies of the salivary glands, our first line of investigation remains an USS-guided core biopsy followed by a full staging of the neck and chest with MRI and CT, respectively. Tumors of the skull base and infratemporal fossa have both MRI and CT for localization of the primary.

For patients with suspected recurrence, especially under a free tissue flap transfer, the preferred modality is a PET-CT. PET-CT allows for a functional evaluation of the suspect area. In areas of previous surgery, the MRI has higher false-positive rates due to loss of fat planes and the inability to differentiate from scarification. A double-contrast CT scan may give better definition of a recurrence; however both specificity and sensitivity are low. The CT may give better spatial resolution. However false-negative results are high in glottic tumors and in mucosal disease with superficial spread with CT.

The role of PET-CT in our practice is limited to neck lumps with unknown primary, small malignancies and in recurrent SCC. The major drawback for a PET-CT is poor anatomical depiction. Anatomical resection is not possible with a PET-CT alone. PET-CT adds little value in patients who have had recent surgery, i.e., biopsy. This invariably gives rise to a hot spot in inflamed tissue. However, it is more sensitive than CT and MRI in detecting small malignancy. In more than $30 \%$ of cases, the PET-CT picks up malignancy not identified by other modalities, and the majority of these are at the tongue base and supraglottic space.

Direct evaluation by examination under anesthesia and pan endoscopy provides probably the most accurate assessment for localization and planning surgery.

\subsubsection{Evaluation of the Neck}

There are numerous papers regarding the sensitivity and specificity of different evaluation techniques-clinical examination, duplex ultrasound scan, CT scan, MRI, and PET. It is agreed by all that clinical examination of the neck provides the least reliable results of all and an adjunct investigation is necessary. It is the opinion of the authors that both CT and MRI give equally reliable results. The decision to which modality suits an individual team the best is reliant on the expertise of the head and neck radiologist in reporting the scans. In our own clinical practice, we feel that the MRI scan provides a good diagnostic value for staging the neck. In T1 tumors where there is a N0 neck clinically and radiologically, the evidence for staging neck dissection is limited. In cases where the MRI is equivocal, an USS with a FNAC (fine needle aspiration cytology) may be indicated. The USS would evaluate the lymph node for size criteria, presence of necrosis, and the absence of normal hilum. Lymph nodes that are rounded and greater than $1 \mathrm{~cm}$ in the neck are regarded to be pathologic until proven otherwise.

The role of USS should not be easily dismissed with the advent of cross-sectional imaging. The USS has many advantages. The spatial resolution of a good USS is better than that of a CT or MRI. Taking account of shape, contour, echogenicity, grouping, internal architecture, necrosis, and pattern of Doppler vascularity enhances the accuracy of US for nodal metastases to greater than $90 \%$.

The USS is a cheap and quick modality that can be used. There is no radiation exposure. Its use as a surveillance scans cannot be surpassed in today's economic constraints. The one major drawback we have noted in our practice is that its sensitivity and specificity are highly operator dependent. It cannot detect retropharyngeal, retrotracheal, and mediastinal 
lymphadenopathy. In these instances a CT or MRI gives better information.

PET-CT has a limited role in the staging of the neck. PET-CT is a useful tool to look at post-chemoradiation treatment response and to evaluate the neck following radiotherapy with residual neck mass. In the head and neck, misregistration of PET to CT can cause difficulty in reporting and increase false-positive results.

\subsubsection{The Role of Sentinel Node Biopsy}

The presence of metastatic disease to the neck is an important prognostic factor for disease-free survival in head and neck cancer. Recent papers by Anil D Cruz et al. have shown that patients who had an elective neck dissection fared much better than those on the watchful waiting strategy in both T1 and T2 tumors [29].

Sentinel node biopsy relies on the fact that metastases to the regional lymph nodes follow a predictive pattern in most cases. Migration of cancer cells is often to the first echelon node. It is therefore predicted that if the first echelon node is negative, the more distal node is unlikely to have cancer cell migration. Validation studies involving elective neck dissection have shown that there is $95 \%$ detection rate in sentinel nodes. The first echelon node in most oral cancers is at level I or level II. In a well-lateralized tumor, the first echelon node more often than not is on the ipsilateral side.

The indications for a sentinel node biopsy are:

1. T1/T2 tumors which are node negative on staging scans.

2. To assess the need for bilateral neck dissection in tumors close to or just crossing the midline.

3. To clarify the need for contralateral neck dissection in large tumors.

Proponents of SLN biopsy claim the following advantages: reduces the morbidity of elective neck dissection, more accurate staging of the neck, and better prediction in those who have an unpredictable pattern of metastatic disease, therefore guides decision-making, helps identify skip metastases and micrometastases, and saves time and expense.

It is the opinion of the authors that sentinel node biopsy is a very good adjunct. Recent meta-analysis and systematic reviews suggest that high sensitivity, negative predictive value, and accuracy of SNB make this a valid diagnostic tool. NICE (National Institute of Clinical Excellence) guidelines recommend that a SLNB should be offered to all patients with T1 and T2 tumors with a node-negative neck. A word of caution, however, for $\mathrm{T} 1$ and $\mathrm{T} 2$ tumors with a tumor thickness greater than $5 \mathrm{~mm}$, an elective neck dissection may still be indicated.

\subsubsection{The Multidisciplinary Team}

Following completion of all diagnostic requisites, the findings are discussed at the weekly MDT or the tumor board meeting. The MDT has a core group of clinicians and healthcare professionals. The MDT comprises of maxillofacial surgeons, ENT surgeons, oncologist, speech and language therapist (SALT), dietician, clinical nurse specialist (CNS), head and neck radiologist, head and neck pathologist, restorative dentist, and cancer audit officer to collect data. We have two clinicians from each of the subspecialties at our MDT. The MDT should not be regarded as a forum to advance individual pride or agenda. This is a group that helps balance evidence base in the management of patients and makes a realistic recommendation of treatment strategy.

The responsibility of the MDT is to protect and facilitate the patients' pathway through cancer treatment. The first and foremost recommendation made by the MDT is the treatment intent-curative or palliative. This is followed by the treatment strategy - surgery or radiotherapy \pm chemotherapy (Refer Chap. 84 to read about Adjunctive therapy in oral cancer).

At our MDT, the nature of surgery or the form of reconstruction is rarely discussed. The certainty of achieving tumor clearance and potential morbidity associated with the treatment form the majority of the discussions. Speech and language team assess the need for potential future PEG (gastrostomy) or nasogastric feed. Where there is a high index of suspicion that a PEG feed will be necessary, this is done pre-treatment. Dieticians help in planning feeding regimes both pre- and postoperatively. The restorative dentist offers an opinion on unrestorable teeth that need to be extracted at the time of surgery or prior to chemoradiation to reduce the incidence of future osteoradionecrosis.

\subsubsection{Planning Reconstruction}

The choice of reconstruction is numerous (Refer Chap. 82 to read about principles of surgical management of oral cancer. Chapter 85 deals with the access osteotomies to maxillofacial region while Chaps. 86 and 88 deals with soft and hard tissue reconstruction respectively). The preferred choice is dependent on the following factors:

- Patient's overall health to withstand long surgery.

- Associated postoperative functional deficit if no reconstruction is carried out.

- Skill of the surgeons.

- Socioeconomic factors. 
The best form of reconstruction is to try and substitute like for like. A simple but effective way of looking at reconstruction would be:

- Flaps for lining the defect in T2 defects-radial forearm free flap, anterolateral thigh perforator flap (ALT), medial sural artery free flap, submental flap, nasolabial flaps.

- Flaps that are required for increasing bulk or low volume-anterolateral thigh flap, pectoralis major flap.

- Flaps for major resection which require high volumerectus flap, latissimus dorsi flap.

- Flaps for lining the pharynx_radial forearm free flap, ALT, pectoralis major flap.

- Skull base defects that require a long pedicle-rectus abdominis flap, ALT, or latissimus dorsi free flap.

- Bone reconstruction-fibula free flap, DCIA (deep circumflex iliac artery) flap, scapula flap.

- Composite defect-combination of the above or scapula flap.

\subsubsection{Conclusion}

A good functional MDT that practices evidence-based medicine with a realistic approach that is patient centered will be an effective oncology team that will deliver high-quality care for patients.

\section{References}

1. Niranjan VR, et al. Oral cancer epidemiology of Aurangabad district (Maharashtra) of India from 2005 to 2014: understanding the burden of disease. Int J Community Med Public Health. 2017 $\mathrm{Jul} ; 4(7): 2275-81$.

2. Gupta B, Ariyawardana A, Johnson NW. Oral cancer in India continues in epidemic proportions: evidence base and policy initiatives. Int Dent J. 2013;63(1):12-25.

3. Park K. Park's textbook of preventive and social medicine. 23rd ed. Jabalpur: M/S Banarsidas Bhanot; 2015.

4. International Agency on Research for Cancer. Smokeless tobacco and some tobacco-specific N-nitrosamines. Monographs, vol. 89. Lyon: IARC; 2007.

5. Murthy NS, Mathew A. Cancer epidemiology, prevention and control. Curr Sci. 2004;86(4):518-27.

6. Gupta PC, Mehta HC. Cohort study of all-cause mortality among tobacco users in Mumbai. India Bull WHO. 2000;78:877-83.

7. Sankaranarayanan R, Duffy SW, Padmakumary G. Tobacco and alcohol as risk factors in the larynx in Kerala. India Int J Cancer. 1990;45:879-82.

8. IARC. Monographs on the evaluation of carcinogenic risk to humans: alcohol drinking, vol. 44. Lyon: IARC; 1988.

9. Kiran Kumar K, Saraswathi TR, Ranganathan K, Devi MU, Elizabeth J. Oral submucous fibrosis: a clinicohistopathological study in Chennai. IJDR. 2007;18:106-11.

10. Anonymous IARC. Tobacco habits other than smoking: betel quid and areca nut chewing and some related nitrosamines. IARC Monogr Eval Carcinog Risk Chem Hum. 1985;37:141-200.
11. Sharma JD, Barman D, Sarma MK, Sharma A, Kalita M, Kataki AC, et al. Burden of head and neck cancers in Kamrup urban district cancer registry of Assam, India: a retrospective study. Int J Res Med Sci. 2014;2:1382-7.

12. Gupta B, Ariyawardana A, Johnson NW. Oral cancer in India continues in epidemic proportions: evidence base and policy initiatives. Int Dent J. 2013;63(1):12-25.

13. Pillai R, Balaram P. Pathogenesis of oral sub mucous fibrosis relationship to risk factors associated with oral cancer. Cancer. 1992;69:2011-20.

14. Roberts $\mathrm{AB}$, Flanders KC, Kondaiah $\mathrm{P}$, Thompson NL, Van Obberghen-Schilling E, et al. Transforming growth factor beta: biochemistry and roles in embryogenesis, tissue repair and remodeling, and carcinogenesis. Recent Prog Horm Res. 1988;44: 157-97.

15. Neville BW, Damm DD. Allen CM - Oral and maxillofacial pathology. 2nd ed. Philadelphia: WB Saunders; 2002. p. 349-50.

16. Thongprasom K, Carrozzo M, Furness S, Lodi G. Interventions for treating oral lichen planus. Cochrane Database Syst Rev. Jul 6, 2011;7:CD001168.

17. Farhi D, Dupin N. Pathophysiology, etiologic factors, and clinical management of oral lichen planus, part I: facts and controversies. Clin Dermatol. 2010;28(1):100-8.

18. Fitzpatrick SG, Hirsch SA, Gordon SC. The malignant transformation of oral lichen planus and oral lichenoid lesions: A systematic review. J Am Dent Assoc. 2014 Jan;145(1):45-56.

19. Pollaers K, Hinton-Bayre A, Friedland PL, Farah CS. AJCC 8th Edition oral cavity squamous cell carcinoma staging - Is it an improvement on the AJCC 7th Edition. Oral Oncol. 2018 Jul;82:23-8.

20. Moore C, Kuhns JG, Greenberg RA. Thickness as prognostic aid in upper aerodigestive tract cancer. Arch Surg. 1986;121(12):1410-4.

21. Mohit-Tabatabai MA, Sobel HJ, Rush BF, Mashberg A. Relation of thickness of floor of mouth stage I and II cancers to regional metastasis. Am J Surg. 1986;152(4):351-3.

22. Brown B, Barnes L, Mazariegos J, Taylor F, Johnson J, Wagner RL. Prognostic factors in mobile tongue and floor of mouth carcinoma. Cancer. 1989;64(6):1195-202.

23. Woolgar JA, Scott J. Prediction of cervical lymph node metastasis in squamous cell carcinoma of the tongue/floor of mouth. Head Neck. 1995;17(6):463-72.

24. O-charoenrat P, Pillai G, Patel S, Fisher C, Archer D, Eccles S, et al. Tumor thickness predicts cervical nodal metastases and survival in early tongue cancer. Oral Oncol. 2003;39:386-90.

25. Ling W, Mijiti A, Moming A. Survival pattern and prognostic factors of patients with squamous cell carcinoma of the tongue: a retrospective analysis of 210 cases. J Oral Maxillofac Surg. 2013;71(4):775-85.

26. Gonzalez-Moles MA, Esteban F, Rodriguez-Archilla A, RuizAvila I, Gonzales-Moles S. Importance of tumour thickness measurement in prognosis of tongue cancer. Oral Oncol. 2002;38: 394-7.

27. Umeda M, Yokoo S, Take Y, Omori A, Nakanishi K, Shimada $\mathrm{K}$. Lymph node metastasis in squamous cell carcinoma of the oral cavity: correlation between histologic features and the prevalence of metastasis. Head Neck. 1992;14(4):263-72.

28. Kane SV, Gupta M, Kakade AC, D'Cruz A. Depth of invasion is the most significant histological predictor of subclinical cervical lymph node metastasis in early squamous carcinomas of the oral cavity. Eur J Surg Oncol. 2006;32:795-803.

29. Thiagarajan S, Nair S, Nair D, Chaturvedi P, Kane SV, Agarwal JP, D'Cruz AK. Predictors of prognosis for squamous cell carcinoma of oral tongue. J Surg Oncol. 2014;109(7):639-44.

30. Morton RP, Ferguson CM, Lambie NK, Whitlock RM. Tumor thickness in early tongue cancer. Arch Otolaryngol Head Neck Surg. 1994;120(7):717-20. 
31. Tai SK, Li WY, Yang MH, Chu PY, Wang YF, Chang PM. Perineural invasion as a major determinant for the aggressiveness associated with increased tumor thickness in t1-2 oral tongue and buccal squamous cell carcinoma. Ann Surg Oncol. 2013;20(11):3568-74.

32. Matsushita Y, Yanamoto S, Takahashi H, Yamada S, Naruse T, Sakamoto Y, Ikeda H, Shiraishi T, Fujita S, Ikeda T, Asahina I, Umeda M. A clinicopathological study of perineural invasion and vascular invasion in oral tongue squamous cell carcinoma. Int $\mathrm{J}$ Oral Maxillofac Surg. 2015;44(5):543-8.

33. Sparano A, Weinstein G, Chalian A, Yodul M, Weber R. Multivariate predictors of occult neck metastasis in early oral tongue cancer. Otolaryngol Head Neck Surg. 2004;131:472-6.

34. Close LG, Brown PM, Vuitch MF, Reisch J, Schaefer SD. Microvascular invasion and survival in cancer of the oral cavity and oropharynx. Arch Otolaryngol Head Neck Surg. 1989;115(11):1304-9.

35. Vincent N, Dassonville O, Chamorey E, Poissonnet G, Pierre CS, Nao EE, Peyrade F, Benezery K, Viel D, Sudaka A, Marcy PY, Vallicioni J, Demard F, Santini J, Bozec A. Clinical and histological prognostic factors in locally advanced oral cavity cancers treated with primary surgery. Eur Ann Otorhinolaryngol Head Neck Dis. 2012;129(6):291-6.

36. de Bondt RB, Nelemans PJ, Hofman PA, et al. Detection of lymph node metastases in head and neck cancer: a meta-analysis comparing US, USg FNAC, CT and MR imaging. Eur J Radiol. 2007;64:266-72.

37. Wu LM, Xu JR, Liu MJ, et al. Value of magnetic resonance imaging for nodal staging in patients with head and neck squamous cell carcinoma: a meta-analysis. Acad Radiol. 2012;19:331-40.

38. Kyzas PA, Evangelou E, Denaxa-Kyza D, et al. 18F-fluorodeoxyglucose positron emission tomography to evaluate cervical node metastases in patients with head and neck squamous cell carcinoma: a meta-analysis. J Natl Cancer Inst. 2008;100:712-20.

39. Som PM, Brandwein-Gensler MS. Lymph nodes of the neck. In: Som PM, Curtin HD, editors. Head \& neck imaging, vol. 2. 5th ed. St Louis: Mosby; 2011. p. 2287-383.

40. Kuriokose M. Contemporary oral oncology, vol. 1 and 2. Cham: Springer International Publishing; 2017.

Open Access This chapter is licensed under the terms of the Creative Commons Attribution 4.0 International License (http://creativecommons. org/licenses/by/4.0/), which permits use, sharing, adaptation, distribution and reproduction in any medium or format, as long as you give appropriate credit to the original author(s) and the source, provide a link to the Creative Commons license and indicate if changes were made.

The images or other third party material in this chapter are included in the chapter's Creative Commons license, unless indicated otherwise in a credit line to the material. If material is not included in the chapter's Creative Commons license and your intended use is not permitted by statutory regulation or exceeds the permitted use, you will need to obtain permission directly from the copyright holder. 